\title{
Testing the Performance of Various Polymeric Antiscalants for Mitigation of Sb-Rich Precipitates Mimicking Stibnite-Based Geothermal Deposits
}

\author{
Celal Çiftçi, ${ }^{1,2}$ Emre Karaburun, ${ }^{1}$ Serhat Tonkul, ${ }^{3}$ Alper Baba, ${ }^{3,4}$ Mustafa M. Demir ${ }^{(D,}{ }^{1}$ \\ and Mehmet İrfan Yeşilnacar ${ }^{2}$ \\ ${ }^{1}$ Department of Materials Science and Engineering, İzmir Institute of Technology, 35430, Gülbahçe, Urla, İzmir, Turkey \\ ${ }^{2}$ Department of Environmental Engineering, Harran University, 63050 Şanlıurfa, Turkey \\ ${ }^{3}$ Program of International Water Resources, İzmir Institute of Technology, 35430, Gülbahçe, Urla, İzmir, Turkey \\ ${ }^{4}$ Department of Civil Engineering, İzmir Institute of Technology, 35430, Gülbahçe, Urla, İzmir, Turkey
}

Correspondence should be addressed to Mustafa M. Demir; mustafamdemir@gmail.com

Received 17 April 2020; Revised 21 June 2020; Accepted 3 July 2020; Published 1 August 2020

Academic Editor: Jinze Xu

Copyright (c) 2020 Celal Çiftçi et al. This is an open access article distributed under the Creative Commons Attribution License, which permits unrestricted use, distribution, and reproduction in any medium, provided the original work is properly cited.

\begin{abstract}
Scaling is frequently observed in geothermal fields and reduces the energy harvesting of power plants. Recently, Sb-rich deposits have developed in many fields around the world. Various polymeric macromolecules have been used as antiscalants to mitigate the formation of scale. Testing potential commercial antiscalants in field conditions is a tedious and costly process. The artificial synthesis of geothermal deposits in the lab is a more practical and economical way to test the performance of antiscalants. This study obtained a Sb-rich deposit by refluxing $\mathrm{SbCl}_{3}$ and $\mathrm{Na}_{2} \mathrm{~S} \cdot 3 \mathrm{H}_{2} \mathrm{O}$ in $18 \mathrm{~h}$. The product was found to be a mixture of $\mathrm{Sb}_{2} \mathrm{O}_{3}$ and $\mathrm{Sb}_{2} \mathrm{~S}_{3}$. We examined the performance of antiscalants such as poly(ethylene glycol), poly(vinyl pyrrolidone), Gelatin, and poly(vinyl alcohol) of various molecular weights at 5 to $100 \mathrm{ppm}$. The formation of $\mathrm{Sb}_{2} \mathrm{~S}_{3}$ is suppressed in the presence of the polymeric antiscalants. The dosage was found to be critical for the solubilization of Sb-rich deposits. Gelatin of $5 \mathrm{ppm}$ showed the highest performance under the conditions employed in this study. While low dosages improve the concentration of [Sb $\left.{ }^{3+}\right]$, high dosages are required to increase the solubility of $\left[\mathrm{S}^{2-}\right]$. Moreover, the amount of deposit is reduced by $12.4 \%$ compared to the reference (in the absence of any polymeric molecules). Thus, comparatively, Gelatin shows the most promising performance among the molecules employed.
\end{abstract}

\section{Introduction}

Scaling is one of the main handicaps for geothermal power plants, as it remarkably reduces energy harvesting. Polymeric antiscalants have been employed to mitigate deposits [1]. Antiscalants prevent the formation of the deposit, reducing power plants' performance and minimizing the occurrence of potential corrosion [2].

The solubility of most species in aqueous solution strongly depends on the thermodynamic properties of the geothermal system. If disperse ions or inactive species are present near their saturation concentration, a slight perturbation in temperature or pressure can result in precipitation for a portion of these ions or species, which often combine and precipitate as a scale on a solid surface with which they come in contact. The equipment and piping in which the solution is confined may be restricted or plugged as a result of scale deposition [3]. Carbonates and silicates are the main scaling chemistry, which is a big problem for both energy harvesting and drinking water supply since the chemistry of scale acts as an insulator [4-10]. In addition, sulfide and sulfur scaling also create similar problems, especially in binary cycle geothermal power plants [10-13]. It is not only a problem of geothermal power plants but also one of the main obstacles frequently encountered in oil fields [14]. Sulfur scaling in geothermal systems can occur in medium, low, and high enthalpy fluids. Criaud and Fouillac (1989) stated that corrosion in low enthalpy areas containing dissolved matter is at 


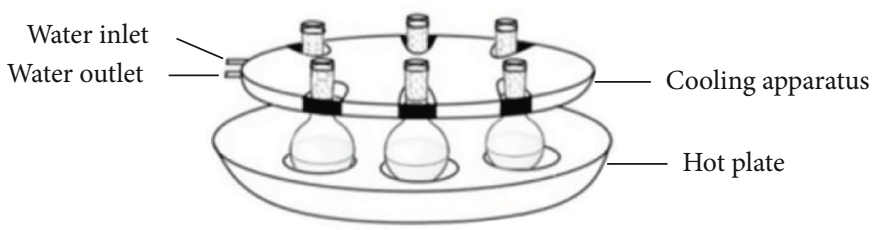

Scheme 1: Experimental setup for the synthesis of Sb-rich deposit.

high concentrations. Corrosive geothermal fluid corrodes casing wells and exposes metals such as $\mathrm{Fe}, \mathrm{Pb}$, and $\mathrm{Zn}$ for aqueous systems [15]. These metals precipitate in metal sulfide form. They are often accompanied by silica precipitation on high-temperature sites. The formation of sulfide deposits has been reported by various plants on the west coast of Turkey [16]. Recently, more emphasis is being placed on antimony (Sb)-rich deposits. While carbonates and silicates have been studied for a long time, little is known about stibnite $\left(\mathrm{Sb}_{2} \mathrm{~S}_{3}\right)$ deposits. Antimony forms stable interaction with sulfur. Antimony is found in sulfide deposits such as stibnite, sulfosalts, and, in some cases, natural Sb [17]. In natural geothermal systems, antimony usually occurs in two oxidation states: trisulfide, $\mathrm{Sb}^{3+}$ and pentasulfide, $\mathrm{Sb}^{5+}[18$, 19]. Sb-rich scaling has been observed in various plants worldwide, including in Turkey, Italy, New Zealand, and El Salvador $[20,21]$. Stibnite $\left(\mathrm{Sb}_{2} \mathrm{~S}_{3}\right)$, known as antimony trisulfide, is a sulfur mineral and is the main component of hydrothermal systems. In recent years, with the prevalence of binary cycle power plants in Turkey, stibnite scaling has also increased [22]. In hydrothermal systems, stibnite precipitation is controlled by $\mathrm{pH}$ and temperature and thus is commonly observed in condensers and heat exchangers where the temperature and $\mathrm{pH}$ may also play an essential role in the thermodynamics of deposition of sulfur-based scales. Although the concentration of antimony in the brine is low, antimony sulfide scaling is a major problem at low temperature and $\mathrm{pH}$ in binary cycle power plants. Typical antimony concentrations are less than one ppm in brine [23]. However, studies have shown that antimony can still be stored as stibnite in natural geothermal systems.

In geothermal systems, stibnite dissolves in water in the form of hydroxide. As the storage of stibnite increases, the concentration of hydrogen sulfide increases. This situation can be expressed simply by the following equation:

$$
\mathrm{Sb}_{2} \mathrm{~S}_{3}+6 \mathrm{H}_{2} \mathrm{O} \longrightarrow 2 \mathrm{Sb}(\mathrm{OH})_{3}+3 \mathrm{H}_{2} \mathrm{~S}
$$

Moreover, stibnite scaling may cause corrosion in natural geothermal systems [12]. Mitigation of the deposit is vital for geothermal power plants.

This work tested various polymeric antiscalants, namely poly(vinyl alcohol) (PVA), polyethylene glycol (PEG), poly(vinyl pyrrolidone) (PVP), and Gelatin, to reduce deposits in geothermal power plants. All these molecules were chosen because they contain functional groups that may interact with the deposit's precursor ions. PVA has hydroxyl groups that can act in functional groups interacting with the main cations $[24,25]$. PEG has oxygen with two lone pairs of electrons on its backbone [9]. PVP contains a cyclic pendant group consisting of amide as an electron-rich species to interact with ions. Gelatin, a biopolymer, possesses both amine and hydroxyl groups in its structure. According to our best knowledge, there is limited literature on the minimization of Sb-rich precipitates mimicking geothermal deposits $[26,27]$. The results of this study showed that Gelatin displayed the most remarkable performance among the antiscalants employed. The product of the reflux was used as an artificial deposit/precipitate in this study. The scale obtained in the real geothermal plant is called a deposit. Both words are used interchangeably in the text.

\section{Experimental}

2.1. Materials. For the synthesis of artificial deposits, a Radleys Carousel 6 Plus Reaction Station (Saffron Walden, UK) was used as the reflux system (Scheme 1). All chemicals were supplied by Sigma-Aldrich (St. Louis, MO, USA) and were used as received without any further purification. Antimony (III) chloride $\left(\mathrm{SbCl}_{3}\right)$ and sodium sulfide trihydrate $\left(\mathrm{Na}_{2} \mathrm{~S} \cdot 3 \mathrm{H}_{2} \mathrm{O}\right)$ were purchased from Sigma-Aldrich (New York, USA). The various molecular weights of polymeric antiscalants were supplied by Sigma-Aldrich: Polyvinyl alcohol (PVA) ( $\mathrm{M}_{\mathrm{w}}: 31-70$, and 146-186 kg/mol), Poly(vinyl pyrrolidone) (PVP) (Mw: 8, and $40 \mathrm{~kg} / \mathrm{mol}$ ), and Poly (ethylene glycol) (PEG) $(0.2 \mathrm{~kg} / \mathrm{mol})$. The chemical structure of the polymeric antiscalants is given in Scheme 2. A Milli-Q Advantage water treatment system produced the deionized water $\left(18.2 \mathrm{M} \Omega \mathrm{cm}-1\right.$ at $\left.25^{\circ} \mathrm{C}\right)$ used in all experiments.

2.2. Methods. The method consists of two stages: the synthesis of artificial deposit and antiscaling performance of the polymeric antiscalants. In the first stage, artificial deposits were synthesized from synthetic brine, which was prepared by mixing an equivolume solution $(50 \mathrm{~mL})$ of antimony (III) chloride $\left(\mathrm{SbCl}_{3}\right)$ and $\mathrm{Na}_{2} \mathrm{~S} \cdot 3 \mathrm{H}_{2} \mathrm{O}$. Synthetic brine was prepared by dissolving $\mathrm{Na}_{2} \mathrm{~S} \cdot 3 \mathrm{H}_{2} \mathrm{O}(0.43 \mathrm{~g} 3.2 \mathrm{mmol})$ and $\mathrm{SbCl}_{3}(0.5 \mathrm{~g}, 2.2 \mathrm{mmol})$ in $100 \mathrm{~mL}$ distilled water. The entire synthetic brine was placed in the reflux system at $100^{\circ} \mathrm{C}$ for $18 \mathrm{~h}$. Afterward, nitrogen gas was passed through for $10 \mathrm{~min}$ and mixed at $400 \mathrm{rpm}$. During the $18 \mathrm{~h}$ period, the solution changed from light orange to dark gray. Subsequently, the reaction mixture was left to cool in the ice bath. After $30 \mathrm{~min}$, the reaction mixture consisted of solid particles in aqueous solutions, which were isolated via centrifugation, and then the leftover decantation solution was collected. In the second stage, the antiscaling performance of the polymers was examined. The chemical structure of the polymers is given in Scheme 2. Polymer solutions $(10 \mathrm{~mL})$ were added to the mixture in various dosages $(5,25,50$, and $100 \mathrm{ppm})$ 
<smiles>CC(C)OCCC(C)(C)O</smiles>

PEG<smiles>CCCC(C)N1CCCC1=O</smiles>

PVP<smiles></smiles>

PVA

(a) PEG

(b) PVP

(c) PVA<smiles>C=C(C)C1CCCN1C(=O)CNC(=O)C1CC(O)CN1C(=O)C(CCC(=O)O)NC(=O)CNC(=O)C(CCCNC(=N)N)NC(=O)C1CCCN1C(=O)CN(C)C(=O)[C@H](C)N</smiles>

(d) Gelatin

Scheme 2: Chemical structure of the polymeric antiscalants employed in this study for the mitigation of the antimony-rich deposit.

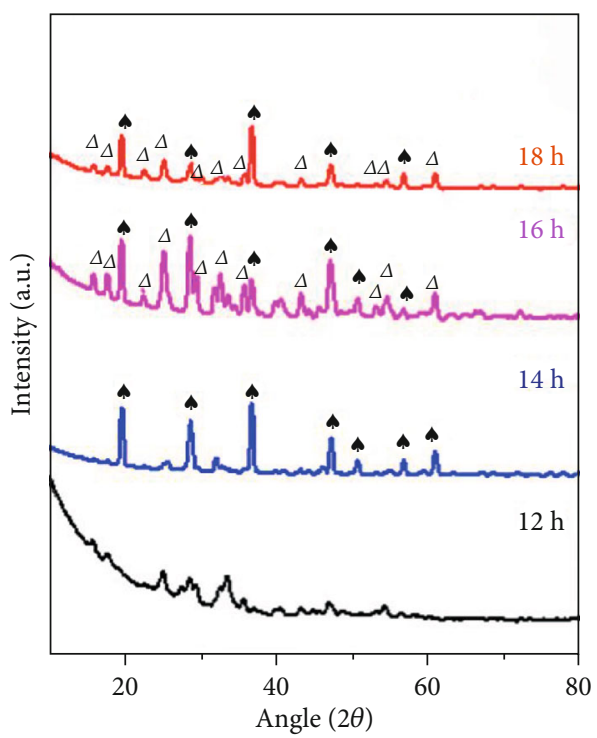

A $\mathrm{Sb}_{2} \mathrm{O}_{3}$

$\triangle \mathrm{Sb}_{2} \mathrm{~S}_{3}$

FIGURE 1: XRD patterns of the precipitates prepared at various reaction times.

to the artificial brine solution $(90 \mathrm{~mL})$. Then, the resulting solution was bubbled through with $\mathrm{N}_{2}$ for $10 \mathrm{~min}$ and placed in the reflux system at $100^{\circ} \mathrm{C}$ for $18 \mathrm{~h}$. The decantate was analyzed by inductively coupled plasma mass spectros-
TABLE 1: The composition of deposit based on Rietveld method. The reference deposit has the following combination $\left(\mathrm{Sb}_{2} \mathrm{~S}_{3}: \mathrm{Sb}_{2} \mathrm{O}_{3}\right)$ (86:14 in terms of mole). The data are obtained from Rietveld method run by using X'Pert HighScore Plus software program.

\begin{tabular}{lccc}
\hline & 25 & 50 & 100 \\
\hline PVA 31 & $0: 100$ & $0: 100$ & $0: 100$ \\
PVA 14.6 & $70: 30$ & $0: 100$ & $0: 100$ \\
PEG & - & $77: 23$ & $77: 23$ \\
Gelatin & $52: 48$ & $0: 100$ & $75: 25$ \\
PVP 58 & $68: 32$ & $67: 33$ & $0: 100$ \\
PVP 8 & $0: 100$ & $0: 100$ & $0: 100$ \\
\hline
\end{tabular}

copy (ICP-MS). Centrifugation was performed to separate the deposit from the decantate. The precipitate was dried at $80^{\circ} \mathrm{C}$ for $12 \mathrm{~h}$ after being centrifuged. Powder X-ray diffraction (XRD) measurements were performed on a PANalytical Powder Diffractometer with a copper $\mathrm{K} \alpha(\lambda=1.5416 \AA)$ tube. The $2 \theta$ was scanned from 10 to $80^{\circ}$ at a scan rate of $0.08^{\circ} \mathrm{s}^{-1}$. The morphology of the precipitates was determined by using a scanning electron microscope (SEM; 300VP, Carl Zeiss, Oberkochen, Germany).

\section{Results and Discussion}

3.1. Structural Characterization of the Sb-Rich Precipitates. For the fabrication of artificial Sb-rich deposits, namely 
precipitate, it is wise to use water-soluble salts of $\mathrm{Sb}$ and $\mathrm{S}$. Refluxing is carried out through the aqueous reaction of $\mathrm{SbCl}_{3}$ and $\mathrm{Na}_{2} \mathrm{~S} \cdot 3 \mathrm{H}_{2} \mathrm{O}$ under ambient conditions. Figure 1 presents the X-ray diffraction patterns of the Sb-rich precipitate obtained at various reaction times. In the beginning, the deposit does not show evident reflections and most probably contains crystalline regions in a large amorphous matrix. As the reaction time is extended to $14 \mathrm{~h}$, an oxide phase that is indexed to valentinite (00-011-0691) forms. The resulting powder is orange. The valentinite is colorless in nature. This orange color may originate from a minute amount of amorphous stibnite, the reflections of which are present in the diffractogram with very weak intensity. Increasing the reaction time to $16 \mathrm{~h}$, the reflections of $\mathrm{Sb}_{2} \mathrm{~S}_{3}$ appear, indicating the formation of the grey-colored sulfide phase (stibnite: 00001-0538) along with the presence of the oxide phase. At $18 \mathrm{~h}$, the products show a similar stable combination of oxide and sulfide. Thus, the reaction time is fixed to $18 \mathrm{~h}$ for the testing of the performance of the antiscalants. Reaction times longer than $18 \mathrm{~h}$ cause the formation of crystals other than oxides and sulfides such as $\mathrm{Sb}_{2} \mathrm{OS}_{2}$ and $\mathrm{Sb}_{4} \mathrm{O}_{5} \mathrm{Cl}_{2}$ (not shown in this text).

Since the product was a mixture of $\mathrm{Sb}_{2} \mathrm{O}_{3}$ and $\mathrm{Sb}_{2} \mathrm{~S}_{3}$, we characterized the mixture with Rietveld refinement analysis of the XRD patterns with X'Pert HighScore Plus. The results are presented in Table 1 . The reference deposit (prepared in the absence of antiscalants) has the following combination $\left(\mathrm{Sb}_{2} \mathrm{~S}_{3}: \mathrm{Sb}_{2} \mathrm{O}_{3}, 86: 14\right.$ in terms of the mole). However, the composition of the product mixture changed in the presence of polymeric antiscalants. The sulfides disappeared, while oxides became a dominant component in the product mixture.

Figure 2 shows an X-ray diffraction patterns of the precipitates prepared in the presence of Gelatin at various dosages. In all diffractograms, the precipitates are the mixture of $\mathrm{Sb}_{2} \mathrm{~S}_{3}$ and $\mathrm{Sb}_{2} \mathrm{O}_{3}$ with varying compositions. However, Gelatin does not influence the crystal structure.

The existence of polymeric antiscalants has a clear influence on the morphology of precipitates. Scanning electron microscopy (SEM) images of the precipitates display the morphology of the deposits (Figure 3 ). The morphology of the precipitates is heterogeneous in nature. There are needles, aggregates of microspheres, dumbbell-shaped crystals, and plates. While the needles, aggregates of microspheres (average diameter: $1.0 \pm 0.8 \mu \mathrm{m}$ ), and dumbbell shape morphologies seem crystal and most probably $\mathrm{Sb}_{2} \mathrm{~S}_{3}$, the plates may refer to $\mathrm{Sb}_{2} \mathrm{O}_{3}$. The morphology of the stibnite-based geothermal deposits has previously been shown [28]. The size and shapes of the precipitates were consistent with the literature [29]. For instance, the needles had $4.8 \pm 3.7 \mu \mathrm{m}$ length and $1.0 \pm 0.8 \mu \mathrm{m}$ width. Plate and dumbbell-shaped morphologies were also observed for some particular crystals. Figure 4(a) shows the crystals prepared in the presence of $50 \mathrm{ppm}$ Gelatin. The needles are split into more substantial and more complex geometrical structures by the assembly of the process of needles. The dumbbell-shaped crystals probably formed from the merging and splinting of the long needles [30]. Figure 4(b) displays the morphology of the precipitates in the presence of $50 \mathrm{ppm}$ PVP. Aggregates of

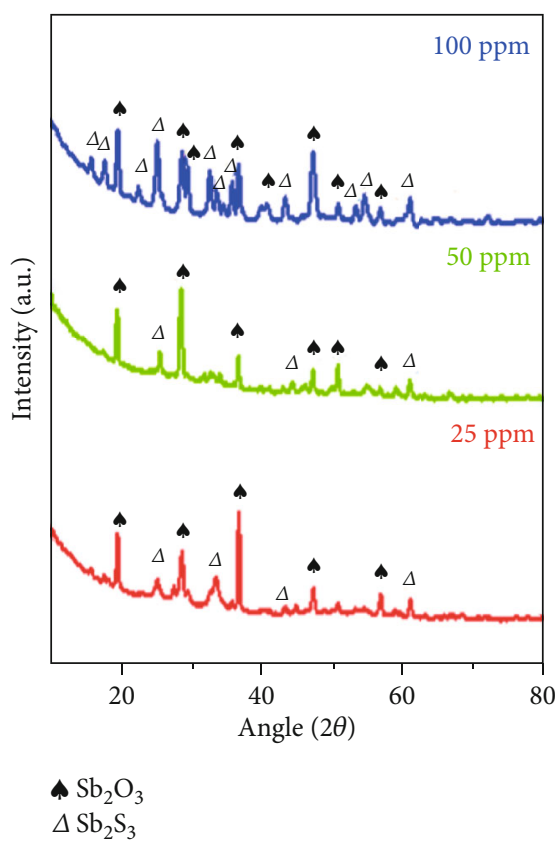

FIGURE 2: XRD patterns of the precipitates prepared in the presence of Gelatin at 25, 50, and $100 \mathrm{ppm}$.

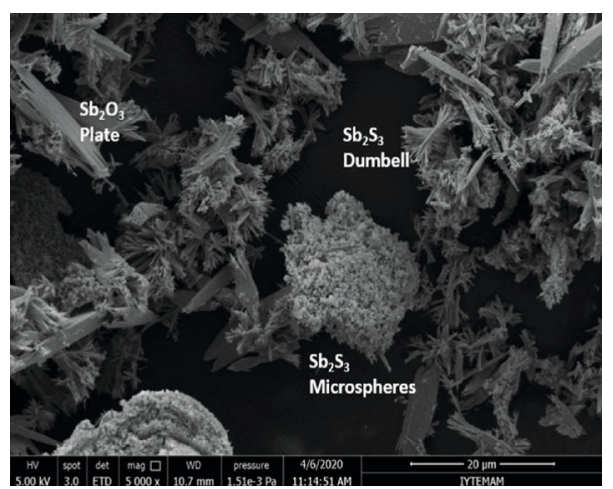

FIGURE 3: SEM image of the reference prepared by refluxing of $\mathrm{SbCl}_{3}$ and $\mathrm{Na}_{2} \mathrm{~S} \cdot 3 \mathrm{H}_{2} \mathrm{O}$ in $18 \mathrm{~h}$. The magnification is $5000 \mathrm{x}$.

spheres (sulfide phase) and a plate of the needles (oxide phase) coexist.

It is crucial to dispose of geothermal fluid by reinjection, either into shallow or deep geothermal wells. The temperature changes may bring about the oversaturation of some minerals such as stibnite, thus creating a tendency to precipitate. It is important to assess the state of mineral saturation in the waste geothermal fluid that will be disposed of by reinjection to find the optimum temperature for reinjection. Figure 5 indicates the activity product for the stibnite and stibnite solubility curve. For example, stibnite is equal to zero at around $100^{\circ} \mathrm{C}$. The degree of supersaturated decreases as the temperature increases, particularly above $100^{\circ} \mathrm{C}$ in geothermal fluid in western Turkey.

The seeping of the polymeric antiscalants into the deposit structure, if it takes place, is a significant question. It becomes an even more critical question since the amount of deposit is used for the determination of antiscalant performance. At 


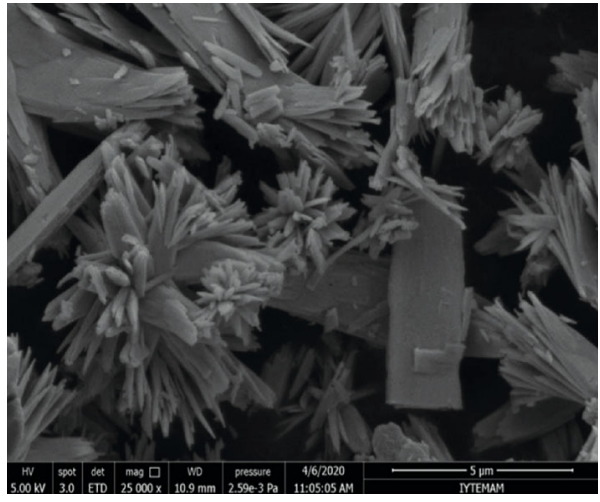

(a)

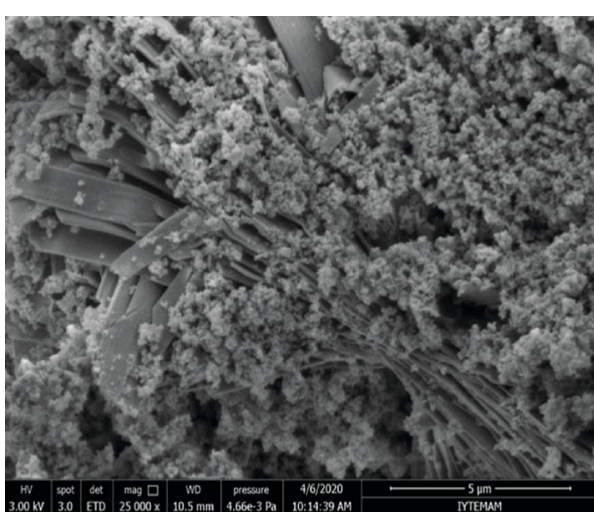

(b)

FIgURE 4: SEM image of the representative samples prepared in the presence of $50 \mathrm{ppm}$ (a) Gelatin and (b) PVP. The magnification is $25000 \mathrm{x}$.

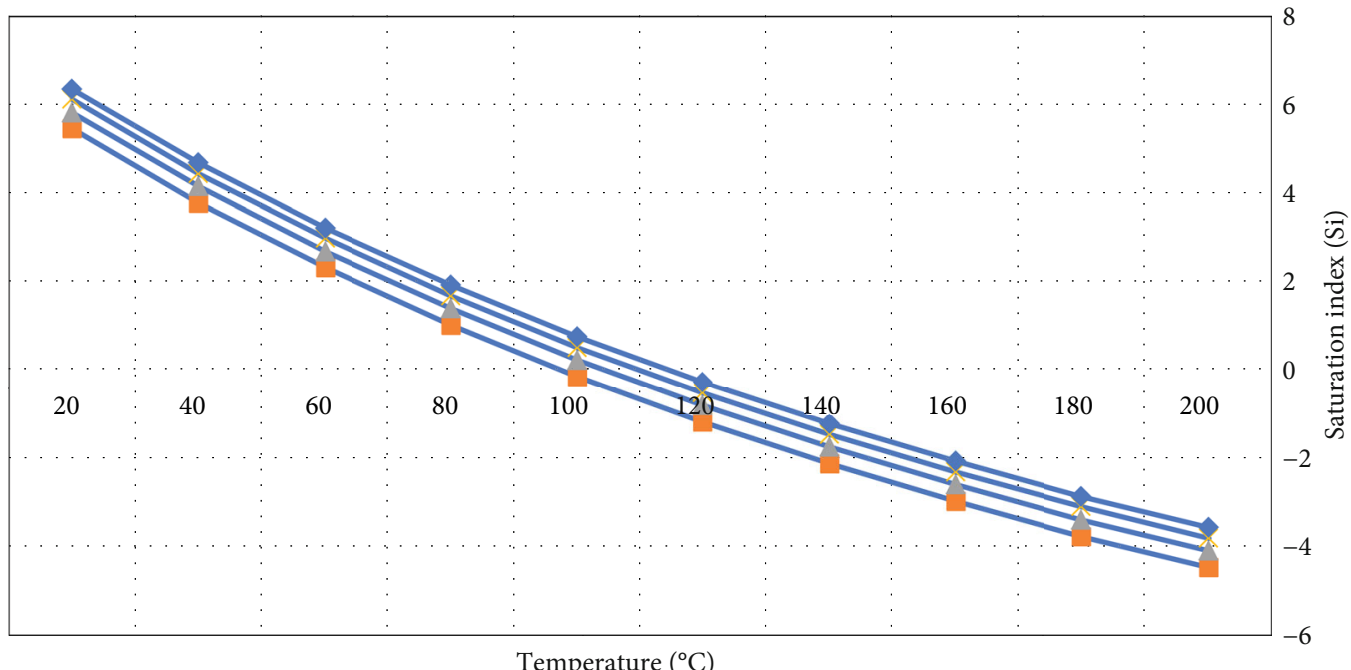

Figure 5: Changes in the state of stibnite in geothermal fluid.

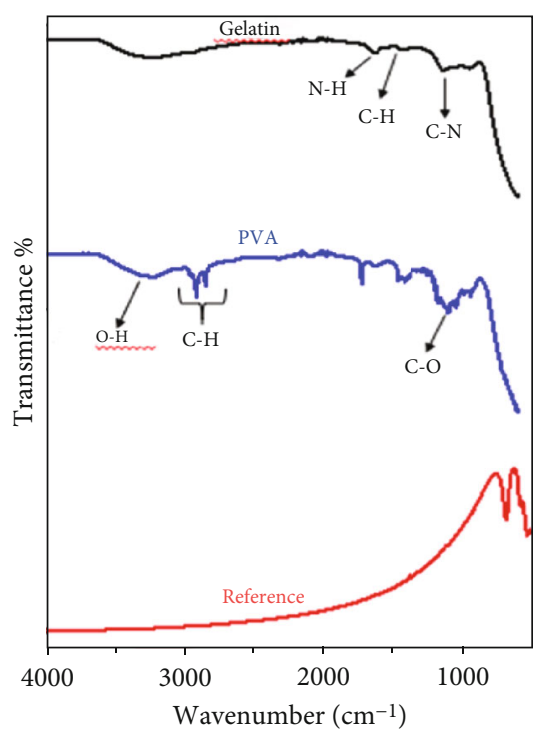

FIGURE 6: Fourier transform infrared spectra of the reference, the precipitate prepared in the presence of 100 ppm PVA and Gelatin. low dosages, the amount of deposit after subtracting the polymeric antiscalant portion is almost unchanged. We could not detect the amount of polymeric antiscalant in the precipitated deposit by thermogravimetry; however, we observed the presence of the antiscalant molecule by vibrational spectroscopy. Figure 6 displays the vibration spectra of the deposits presented in the absence and presence of the polymeric antiscalants. While the reference does not show vibrational signals in the infrared region, the precipitates prepared in the presence of PVA and Gelatin show characteristic signals of specific bonds that belong to the polymer of interest. For instance, the one prepared in the presence of Gelatin showed characteristic bending at $1649 \mathrm{~cm}^{-1}$ of $\mathrm{N}-\mathrm{H}$ bond. Another characteristic signal of Gelatin could be seen at $1144 \mathrm{~cm}^{-1}$ of C-N stretching. Thus, the combination of both thermogravimetry and spectroscopy results suggest that a small amount of polymeric antiscalant remains in the deposit.

3.2. Performance of the Antiscalants. Using antiscalant in the model reaction, there are two success criteria: (i) the decrease of the amount of precipitate; (ii) the concentration of the ions 
TABLe 2: Concentration of several of ions $\left(\mathrm{mg} \cdot \mathrm{L}^{-1}\right)$ in the decantate solution after isolation of solid content so-called deposit. Dosage of the antiscalants is $5 \mathrm{ppm}$. The reference points out the reaction carried out in absence of antiscalants.

\begin{tabular}{lcccccc}
\hline Antiscalants & {$\left[\mathrm{Na}^{+}\right]$} & {$\left[\mathrm{S}^{=}\right]$} & {$\left[\mathrm{Sb}^{\mathrm{n}+}\right]$} & The amount of deposit & $\begin{array}{c}\text { The amount of deposit after } \\
\text { subtraction of the polymer/mg }\end{array}$ & $\begin{array}{c}\text { The amount of deposit after } \\
\text { subtraction of the polymer }\end{array}$ \\
\hline Reference & 980 & 56 & 22 & 290 & 290 & 0 \\
PVA 31 & 1160 & 20 & 64 & 313 & 313 & 0 \\
PVA 14.6 & 1190 & 21 & 51 & 283 & 283 & 0 \\
Gelatin & 1170 & 15 & 62 & 254 & 254 & 0 \\
PVP & 1170 & 18 & 79 & 260 & 260 & 0 \\
\hline
\end{tabular}

in the decantate such as $\mathrm{Sb}^{3+}$ and $\mathrm{S}^{2-}$ after the isolation of precipitate. Table 2 presents the concentrations of $\mathrm{Na}^{+}$, $\mathrm{Sb}^{3+}$, and $\mathrm{S}^{2-}$ left in the decantate solution in terms of $\mathrm{ppm}$. Independent of the chemistry of the antiscalants, the concentration of the $\mathrm{Sb}^{3+}$ increases in the presence of antiscalants. An electrostatic interaction may take place between $\mathrm{Sb}$ cations and electron-rich groups on the backbone of polymeric antiscalants such as hydroxyl for PVA, oxygen of PEG, the nitrogen of pyrrolidone and hydroxyl and amine groups of Gelatin. Thus, both $\mathrm{Na}^{+}$and $\mathrm{Sb}^{3+}$ are held in the solution and do not contribute to the formation of solid precipitated by the aforementioned groups. However, the antiscalants were not as effective as in the dissolution of the sulfur ions. Most probably, they do not have positively charged (or at least partially positively charged) functional groups on their backbone; therefore, negatively charged sulfur anions are not able to find available sites on polymeric molecules to interact with. Reduction of the amount of precipitate is another criterion for the performance of antiscalants; in fact, it is the main motivation for using antiscalants in the geothermal fields. In the model reaction, the amount of precipitate is also studied. The reference sample provides $290 \mathrm{mg}$ of the precipitate. The ones prepared in the presence of the antiscalants are lower than this value, except PVA $31-70 \mathrm{~kg} / \mathrm{mol}$ by which the amount of precipitate is above the reference point most, probably due to the existence of polymeric molecules in the precipitate. The maximum reduction of the solid deposit that refers to scaling in real fields is obtained by the application of Gelatin (nearly \%12.4). Considering that a certain amount of polymeric antiscalant is kept inside the precipitate as the vibrational spectroscopy suggests, the reduction of the amount of deposit may be even higher in terms of percentage.

The dosage of the antiscalant was also examined, taking Gelatin as a representative example. Dosages higher than 5 ppm were studied: 25, 50, and $100 \mathrm{ppm}$. The concentration of the ions and the amount of deposit after the reaction are given in Table 3. The application of $5 \mathrm{mg}$ of Gelatin increases the concentration of Sb from 22 to $62 \mathrm{ppm}$. As the dosage of antiscalant increases, the concentration of $\mathrm{Sb}$ remains almost unchanged compared to the reference sample. It seems that Gelatin only works for low dosage. In contrast, the concentration of sulfur increases as the dosage increases. At 5 ppm, $5 \mathrm{ppm}$ sulfur concentration is lower than that of the reference and gradually increases as the dosage increases to
$96 \mathrm{ppm}$. Thus, the polymeric antiscalant was found to play the opposite effect on the concentration of the $\mathrm{Sb}^{3+}$ and $\mathrm{S}^{2-}$ ions. While the $\mathrm{Sb}$ ion was suspended in the decantate solution at low dosages, $\left[\mathrm{S}^{2-}\right]$ was found to be higher compared to that of the reference. A similar trend is seen in other antiscalants (Figure 7).

At low dosages, the amount of deposit decreased from $290 \mathrm{mg}$ to $254 \mathrm{mg}$. The lowest was recorded when $25 \mathrm{ppm}$ was applied (18\%). At the highest dosage of 100 ppm antiscalant, the amount of deposit was even higher $(337 \mathrm{mg})$. The remarkable increase in the amount of precipitate at high dosages may have originated from flocculation (Scheme 3).

Briefly, flocculation is a process that promotes agglomeration of the particles by the help of a high dosage of the long polymeric chain. As a result, sedimentation of the particles takes place. Meanwhile, the settling of the particles is assisted by the presence of flocculants, which are organic molecules. A long polymer chain interacts with more than one particle such that agglomeration occurs and the agglomerated structure has a larger massive structure. At high dosages, flocculation may be the main mechanism taking place.

\section{Conclusions}

This paper presented a model lab reaction to test potential polymeric antiscalants against $\mathrm{Sb}$-rich scaling. We examined a simple reaction between $\mathrm{Sb}$ and $\mathrm{S}$ salts under ambient conditions. In short reaction times $(12 \mathrm{~h})$, the product was $\mathrm{Sb}_{2} \mathrm{O}_{3}$. The formation of $\mathrm{Sb}_{2} \mathrm{~S}_{3}$ occurred gradually when the reaction time was extended to $18 \mathrm{~h}$. Saturation index based on thermodynamic consideration suggests the formation of stibnite. The performance of the antiscalants was found to be strongly dependent on the dosage. A low dosage of polymeric antiscalants helped to increase the concentration of antimony ions in the decantate; on the other hand, high dosages improved the solubilization of sulfur ions. The antiscalants remarkably reduced the amount of precipitate. Gelatin was found to be the most promising antiscalant among those employed in this study. The amount of precipitate increased at high dosages, most probably due to the occurrence of flocculation. To investigate ways to improve the performance of antiscalants, a computational study focusing on the calculation of binding energy between $\mathrm{Sb}^{3+} / \mathrm{S}^{2-}$ ions and functional groups in aqueous systems should be performed. The functional groups should have high binding energy to the constituent atoms of the deposit. 
TABLE 3: The effect of Gelatin at various dosages. The concentration of the ions is given in terms of ppm. The amount of polymeric antiscalant remains in the deposit is determined by gravimetry.

\begin{tabular}{lcccccc}
\hline Dosage/ppm & {$\left[\mathrm{Na}^{+}\right]$} & {$\left[\mathrm{S}^{=}\right]$} & {$\left[\mathrm{Sb}^{\mathrm{n}+}\right]$} & The amount of deposit/mg & $\begin{array}{c}\text { The amount of deposit after } \\
\text { subtracting of the polymer/mg }\end{array}$ & $\begin{array}{c}\text { The amount of polymer } \\
\text { remaining in the deposit/mg }\end{array}$ \\
\hline Reference & 980 & 56 & 22 & 290 & 254 & 0 \\
5 & 1170 & 16 & 62 & 254 & 235 & 2 \\
25 & 1660 & 60 & 10 & 237 & 278 & 5 \\
50 & 1260 & 89 & 14 & 283 & 337 & 10 \\
100 & 1370 & 96 & 12 & 347 & & \\
\hline
\end{tabular}

$\left[\mathrm{Sb}^{3+}\right]$

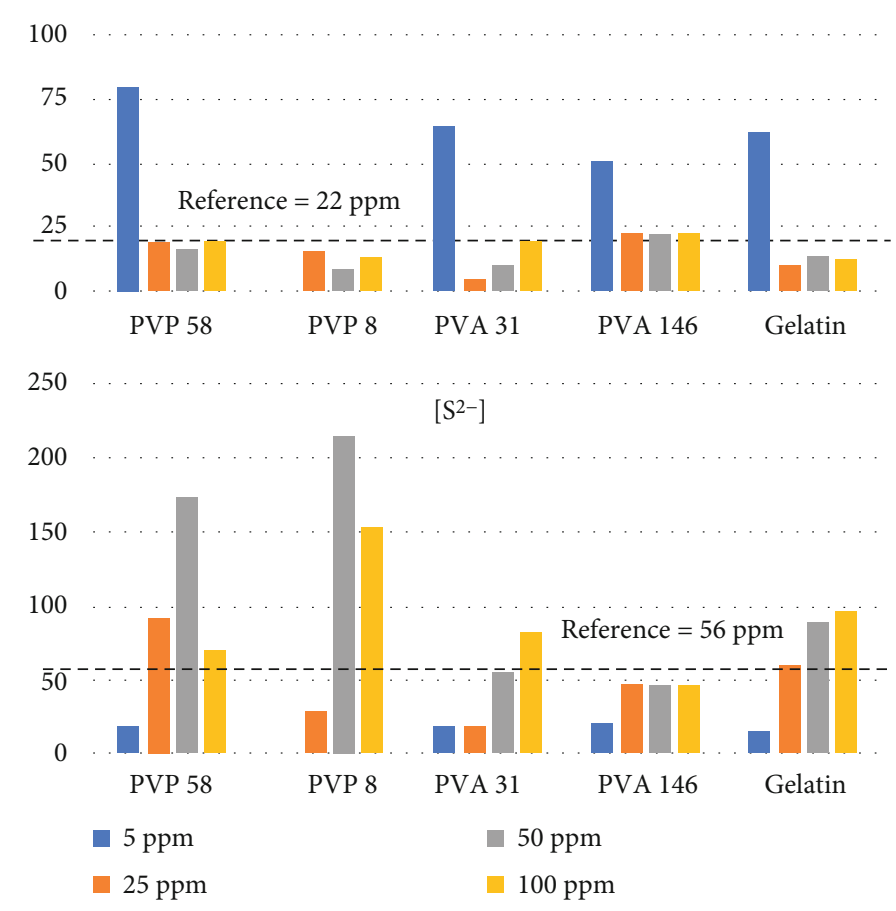

FIGURE 7: The concentration of $\mathrm{Sb}^{3+}$ and $\mathrm{S}^{2-}$ in the presence of the antiscalants at all dosages. The dashed line represents the concentration of the ion of interest for reference (without antiscalants).

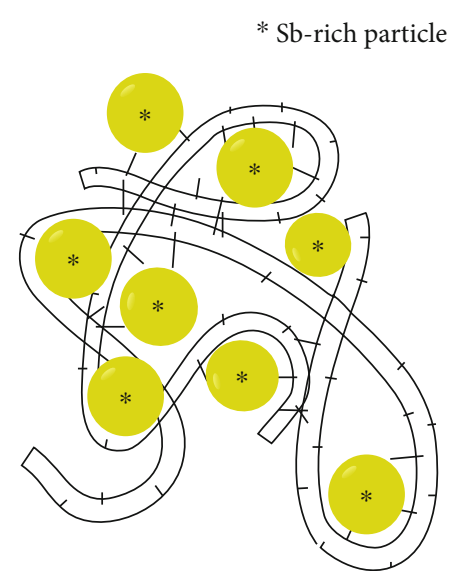

Scheme 3: Schematic representation of flocculation.

\section{Appendix \\ A.1. Thermodynamic Consideration of Saturation Index}

The composition of geothermal fluids is derived from water, steam, and gas samples collected at the thermal spring, production wells, and reinjection wells. Many studies show that geothermal fluid compositions are controlled by mineral-solution equilibria with respect to various elements [31-40]. Changes which occur in temperature and fluid composition during boiling between reservoir and wellhead, generally lead to changes in mineral saturation. Such changes may result in mineral precipitation or mineral dissolution. The activity products for these minerals such as calcite, aragonite, pyrite, stibnite, and quartz were calculated. The data usually required for speciation calculations are a chemical analysis of the water, including $\mathrm{pH}$, Eh, and 
temperature, and thermodynamic data for all reactions considered. The distribution of species in solution is solved by the aqueous model using mass action and mass balance equations. From the calculated distribution of species equilibrium, partial pressures of gases may be calculated, as well as the saturation state of the solution with respect to appropriate mineral phases [41]. The fundamental criterion for chemical equilibrium in a thermodynamic system is that the total Gibbs free energy be at a minimum. At constant temperature and pressure, the Gibbs free energy change in a chemical reaction is given by:

$$
\Delta G=\sum V_{p} \cdot \mu_{p}-\sum V_{r} \cdot \mu_{r}
$$

Where both $\mu_{\mathrm{p}}$ and $\mu_{\mathrm{r}}$ are chemical potentials for the product and reactant species, respectively, and $\mathrm{V}_{\mathrm{p}}$ and $\mathrm{V}_{\mathrm{r}}$ are the corresponding stoichiometric coefficients. The chemical potentials are given by

$$
\begin{gathered}
\mu_{p}=\mu_{p}+R T \ln a_{p} \\
\mu_{r}=\mu_{r}+R T \ln a_{r}
\end{gathered}
$$

where the superscript/indicates the standard state;

$R=$ the gas constant;

$T=$ the absolute temperature; and.

$a_{p}$ and $a_{r}=$ the activity of the product and reactant species, respectively.

Substituting, we find that:

$$
\begin{aligned}
\Delta G & =\sum_{P} V_{p}\left[\mu_{p}+R T \ln a_{p}\right]-\sum_{r} V_{r}\left[\mu_{r}+R T \ln a_{r}\right] \\
& =\sum_{P} V_{p} \mu_{p}-\sum_{r} V_{r} \mu_{r}+R T \sum_{P} \ln \left(a_{p}^{V p}\right)-R T \sum_{r} \ln \left(a_{r}^{V r}\right)
\end{aligned}
$$

and

$$
\Delta G=\Delta G+R T \sum_{P} \ln \left(a_{i}^{V i}\right)=\Delta G+R T \ln \prod\left(a_{i}{ }^{V i}\right)
$$

Where $\Delta \mathrm{G}$ is the Standard Gibbs free energy of reaction, and the summation goes over all reactants and products; $\mathrm{v}_{\mathrm{i}}$ is positive for products and negative for reactants.

The ion activity product is defined by:

$$
Q=\prod\left(a_{i}^{V i}\right)=\frac{a_{A}^{V A} \cdot a_{B}{ }^{V B} \cdots}{a_{M}^{V M} \cdot a_{N}^{V N} \cdots}
$$

At equilibrium, $\Delta G=0$ and $Q=K$, where $K$ is the equilibrium constant. For mineral-solute equilibrium, this constant is usually called the solubility product constant. Thus,

$$
\begin{aligned}
& \Delta G=-R T \ln K \\
& \Delta G=-R T \ln K+R T \ln Q=R T \ln \frac{Q}{K}
\end{aligned}
$$

For a reaction between an aqueous solution and a mineral, the saturation index is defined in terms of the saturation index $(S I)$

$$
S I=\log \frac{Q}{K}
$$

Where $Q$ is the ion activity product for the mineral-water reaction and $K$ is the equilibrium constant. The saturation index is a measure of departure from equilibrium. It is equal to zero at equilibrium, positive if the solution is supersaturated and negative if it is undersaturated.

\section{Data Availability}

The work we describe here in an article can potentially be replicated.

\section{Conflicts of Interest}

The authors declare that they have no conflicts of interest.

\section{Acknowledgments}

The authors thank the Scientific Research Projects Committee of Harran University (HUBAP) under grant no.19231. Microscopy and diffraction were carried out in the Center for Materials Research of the Izmir Institute of Technology. The authors thank Katherine Willcox Özsarı for correcting the language of the manuscript.

\section{References}

[1] M. Preari, K. Spinde, J. Lazic, E. Brunner, and K. D. Demadis, "Bioinspired insights into silicic acid stabilization mechanisms: the dominant role of polyethylene glycol-induced hydrogen bonding," Journal of the American Chemical Society, vol. 136, no. 11, pp. 4236-4244, 2014.

[2] R. Singh, "Water and membrane treatment," in Hybrid Membrane Systems for Water Purification, R. Singh, Ed., pp. 57130, Elsevier Science, Amsterdam, 2005.

[3] Z. Amjad and K. D. Demadis, Mineral scales and deposits: scientific and technological approaches, Elsevier, 2015.

[4] A. D. Atasoy and M. I. Yesilnacar, "Effect of high sulfate concentration on the corrosivity: a case study from groundwater in Harran Plain, Turkey," Environmental Monitoring and Assessment, vol. 166, no. 1-4, pp. 595607, 2010.

[5] A. Baba, M. M. Demir, G. A. Koc, and C. Tugcu, "Hydrogeological properties of hyper-saline geothermal brine and application of inhibiting siliceous scale via $\mathrm{pH}$ modification," Geothermics, vol. 53, pp. 406-412, 2015.

[6] M. M. Demir, A. Baba, V. Atilla, and M. Inanl,, "Types of the scaling in hyper saline geothermal system in northwest Turkey," Geothermics, vol. 50, pp. 1-9, 2014.

[7] D. L. Gallup and E. J. G. Barcelon, "Investigations of organic inhibitors for silica scale control from geothermal brines-II," Geothermics, vol. 34, no. 6, pp. 756-771, 2005.

[8] A. Spinthaki, J. Matheis, W. Hater, and K. D. Demadis, "Antiscalant-driven inhibition and stabilization of 
"Magnesium silicate" under geothermal stresses: the role of magnesium-Phosphonate coordination chemistry," Energy \& Fuels, vol. 32, no. 11, pp. 11749-11760, 2018.

[9] G. Topcu, A. Celik, A. Kandemir, A. Baba, H. Sahin, and M. M. Demir, "Increasing solubility of metal silicates by mixed polymeric antiscalants," Geothermics, vol. 77, pp. 106-114, 2019.

[10] F. S. Tut Haklıdır and T. Özen Balaban, "A review of mineral precipitation and effective scale inhibition methods at geothermal power plants in West Anatolia (Turkey)," Geothermics, vol. 80, pp. 103-118, 2019.

[11] M. Azaroual, C. Kervévan, M. N. Durance, and P. Durst, "SCALE 2000: reaction-transport software dedicated to thermokinetic prediction and quantification of scales applicability to desalination problems," Desalination, vol. 165, pp. 409-419, 2004.

[12] A. Ellis and W. Mahon, Chemistry and Geothermal Systems Academic Press New York, p. 392, 1977.

[13] A. G. Reyes, W. J. Trompetter, K. Britten, and J. Searle, "Mineral deposits in the Rotokawa geothermal pipelines, New Zealand," Journal of Volcanology and Geothermal Research, vol. 119, no. 1-4, pp. 215-239, 2003.

[14] N. Mundhenk, P. Huttenloch, B. Sanjuan, T. Kohl, H. Steger, and Z. RJCS, "Corrosion and scaling as interrelated phenomena in an operating geothermal power plant," Corrosion Science, vol. 70, pp. 17-28, 2013.

[15] M. I. Yesilnacar and I. Yenigun, "Effect of irrigation on a deep aquifer: a case study from the semi-arid Harran Plain, GAP Project, Turkey," Bulletin of Engineering Geology and the Environment, vol. 70, no. 2, pp. 213-221, 2011.

[16] M. Inanli and V. Atilla, "Metal Silicate Formation at Tuzla Geothermal Brine Lines," in Proceedings International Workshop on Mineral Scaling, Manila, Philippines, 2011.

[17] A. E. Williams-Jones and C. J. E. G. Norman, "Controls of mineral parageneses in the system Fe-Sb-S-O," Economic Geology, vol. 92, no. 3, pp. 308-324, 1997.

[18] R. E. Stauffer and J. M. Thompson, "Arsenic and antimony in geothermal waters of Yellowstone National Park, Wyoming, USA," Geochimica et Cosmochimica Acta, vol. 48, no. 12, pp. 2547-2561, 1984.

[19] D. E. White, "Mercury and base-metal deposits with associated thermal and mineral waters," Geochemistry of Hydrothermal Ore Deposits, pp. 575-631, 1967.

[20] K. Brown, Mineral Scaling in Geothermal Power Production, United Nations University, Iceland, 2013.

[21] N. Wilson, J. Webster-Brown, and K. Brown, "Controls on stibnite precipitation at two New Zealand geothermal power stations," Geothermics, vol. 36, no. 4, pp. 330-347, 2007.

[22] S. J. Zarrouk, B. C. Woodhurst, and C. Morris, "Silica scaling in geothermal heat exchangers and its impact on pressure drop and performance: Wairakei binary plant, New Zealand," Geothermics, vol. 51, pp. 445-459, 2014.

[23] K. Brown, "Antimony and Arsenic Sulfide Scaling in Geothermal Binary Plants," in Proceedings International Workshop on Mineral Scaling, 2011.

[24] A. Celik, G. Koc, E. Erdogan, T. Shahwan, A. Baba, and M. M. Demir, "Use of electrospun fiber mats for the remediation of hypersaline geothermal brine," Desalination and Water Treatment, vol. 62, pp. 94-100, 2017.
[25] A. Celik, G. Topcu, A. Baba, Y. Akdogan, U. Senturk, and M. M. Demir, "Experimental modeling of silicate-based geothermal deposits," Geothermics, vol. 69, pp. 65-73, 2017.

[26] J. S. Gill, L. Muller, and D. Rodman, "Inhibition of antimony sulfide (stibnite) scale in geothermal fields," GRC Transactions, vol. 37, pp. 899-904, 2013.

[27] L. Muller, J. S. Gill, D. Rodman, K. Brown, and R. Robinson, Control of Metal Sulfide Deposits in Geothermal Binary Plants, Proceeding World geothermal Congress, Melbourne, Australia, 2015.

[28] N. Yildirim and A. Yildirim, "High total inorganic carbon concentration dependent carbonate scaling and mitigation system in moderate to high enthalpy geothermal fields in Turkey," in Proceedings of the World Geothermal Congress, pp. 25-29, Melbourne, Australia, 2015.

[29] J. Pan, S. Xiong, B. Xi et al., "Tartatric acid and L-cysteine synergistic-assisted synthesis of antimony trisulfide hierarchical structures in aqueous solution," European Journal of Inorganic Chemistry, vol. 2009, no. 35, pp. 5302-5306, 2009.

[30] T. Guner, A. Kus, M. Ozcan, A. Genc, H. Sahin, and M. M. Demir, "Green fabrication of lanthanide-doped hydroxidebased phosphors: $\mathrm{Y}(\mathrm{OH}) 3$ : Eu3+ nanoparticles for white light generation," Beilstein journal of nanotechnology, vol. 10, no. 1, pp. 1200-1210, 2019.

[31] S. Arnórsson, "The quartz-and $\mathrm{Na} / \mathrm{K}$ geothermometers: II. Results and application for monitoring studies," in Proceedings of the World Geothermal Congress, pp. 935-940, KyushuTohoku Japan, 2000.

[32] S. Arnórsson, E. Gunnlaugsson, and H. Svavarsson, "The chemistry of geothermal waters in Iceland. II. Mineral equilibria and independent variables controlling water compositions," Geochimica et Cosmochimica Acta, vol. 47, no. 3, pp. 547-566, 1983.

[33] A. Baba, F. Şaroğlu, I. Akkuş et al., "Geological and hydrogeochemical properties of geothermal systems in the southeastern region of Turkey," Geothermics, vol. 78, pp. 255$271,2019$.

[34] W. F. Giggenbach, "Geothermal solute equilibria. derivation of $\mathrm{Na}-\mathrm{K}-\mathrm{Mg}$-Ca geoindicators," Geochimica et Cosmochimica Acta, vol. 52, no. 12, pp. 2749-2765, 1988.

[35] B. T. Gudmundsson and S. Arnórsson, "Secondary mineral-fluid equilibria in the Krafla and Námafjall geothermal systems, Iceland," Applied Geochemistry, vol. 20, no. 9, pp. 1607-1625, 2005.

[36] I. Gunnarsson and S. Arnórsson, “Amorphous silica solubility and the thermodynamic properties of $\mathrm{H} 4 \mathrm{SiO} 4$ in the range of 0 to 350 C at Psat," Geochimica et Cosmochimica Acta, vol. 64, no. 13, pp. 2295-2307, 2000.

[37] G. Michard, "The physical chemistry of geothermal systems," in Application of geochemistry in geothermal reservoir development, F. D'Amore, Ed., pp. 197-214, UNITAR/UNDP Publication, Rome, 1991.

[38] A. Stefánsson, S. Arnórsson, I. Gunnarsson, H. Kaasalainen, and E. Gunnlaugsson, "The geochemistry and sequestration of $\mathrm{H} 2 \mathrm{~S}$ into the geothermal system at Hellisheidi, Iceland," Journal of Volcanology and Geothermal Research, vol. 202, no. 3-4, pp. 179-188, 2011.

[39] G. Tarcan, Aquifer Chemistry and Mineral Saturation in Selected High Temperature Geothermal Areas, University, United Nations, 2001. 
[40] M. P. Tole, H. Ármannsson, P. Zhong-He, and S. Arnórsson, "Fluid/mineral equilibrium calculations for geothermal fluids and chemical geothermometry," Geothermics, vol. 22, no. 1, pp. 17-37, 1993.

[41] L. N. Plummer, D. L. Parkhurst, and D. C. Thorstenson, "Development of reaction models for ground-water systems," Geochimica et Cosmochimica Acta, vol. 47, no. 4, pp. 665685, 1983. 